\title{
RESEARCH
}

Open Access

\section{Identification of the defense-related gene VdWRKY 53 from the wild grapevine Vitis davidii using RNA sequencing and ectopic expression analysis in Arabidopsis}

Ying Zhang ${ }^{1}$, Jia-Long Yao ${ }^{2}$, Hu Feng ${ }^{1}$, Jianfu Jiang ${ }^{1}$, Xiucai Fan ${ }^{1}$, Yun-Fei Jia ${ }^{1}$, Ran Wang ${ }^{1}$ and Chonghuai Liu ${ }^{1 *}$

\begin{abstract}
Background: Grapevine is an important fruit crop grown worldwide, and its cultivars are mostly derived from the European species Vitis vinifera, which has genes for high fruit quality and adaptation to a wide variety of climatic conditions. Disease resistance varies substantially across grapevine species; however, the molecular mechanisms underlying such variation remain uncharacterized.

Results: The anatomical structure and disease symptoms of grapevine leaves were analyzed for two grapevine species, and the critical period of resistance of grapevine to pathogenic bacteria was determined to be $12 \mathrm{~h}$ post inoculation (hpi). Differentially expressed genes (DEGs) were identified from transcriptome analysis of leaf samples obtained at 12 and $36 \mathrm{hpi}$, and the transcripts in four pathways (cell wall genes, LRR receptor-like genes, WRKY genes, and pathogenesis-related (PR) genes) were classified into four co-expression groups by using weighted correlation network analysis (WGCNA). The gene VdWRKY53, showing the highest transcript level, was introduced into Arabidopsis plants by using a vector containing the CaMV35S promoter. These procedures allowed identifying the key genes contributing to differences in disease resistance between a strongly resistant accession of a wild grapevine species Vitis davidii (VID) and a susceptible cultivar of V. vinifera, 'Manicure Finger' (VIM). Vitis davidii, but not VIV, showed a typical hypersensitive response after infection with a fungal pathogen (Coniella diplodiella) causing white rot disease. Further, 20 defense-related genes were identified, and their differential expression between the two grapevine species was confirmed using quantitative real-time PCR analysis. VdWRKY53, showing the highest transcript level, was selected for functional analysis and therefore over-expressed in Arabidopsis under the control of the CaMV35S promoter. The transgenic plants showed enhanced resistance to C. diplodiella and to two other pathogens, Pseudomonas syringae pv. tomato DC3000 and Golovinomyces cichoracearum.
\end{abstract}

Conclusion: The consistency of the results in VID and transgenic Arabidopsis indicated that VdWRKY53 might be involved in the activation of defense-related genes that enhance the resistance of these plants to pathogens. Thus, the over-expression of VdWRKY53 in transgenic grapevines might improve their resistance to pathogens.

Keywords: Chinese wild grapevine, Disease resistance, Grapevine white rot, Transcriptome, VdWRKY53 transcription factor

\footnotetext{
* Correspondence: liuchonghuai@caas.cn

${ }^{1}$ Zhengzhou Fruit Research Institute, Chinese Academy of Agriculture

Sciences, Zhengzhou 450009, China

Full list of author information is available at the end of the article
}

(c) The Author(s). 2019 Open Access This article is distributed under the terms of the Creative Commons Attribution 4.0 International License (http://creativecommons.org/licenses/by/4.0/), which permits unrestricted use, distribution, and reproduction in any medium, provided you give appropriate credit to the original author(s) and the source, provide a link to the Creative Commons license, and indicate if changes were made. The Creative Commons Public Domain Dedication waiver (http://creativecommons.org/publicdomain/zero/1.0/) applies to the data made available in this article, unless otherwise stated. 


\section{Background}

Grapevine is an important fruit crop grown worldwide, and its cultivars are mostly derived from the European species Vitis vinifera, which has genes for high fruit quality and adaptation to a wide variety of climatic conditions. However, $V$. vinifera cultivars are susceptible to many pathogens such as phytoplasmas, viruses, bacteria, oomycetes, and fungi [1].

The fungus Coniella diplodiella (Speg.) Petr. \& Syd., which belongs to family Schizoparmaceae, causes the devastating white rot disease on grape berries at the ripening stage, resulting in partial to total crop losses. This disease also has severe impacts on the environment because repeated fungicide applications are required to control it. White rot disease is a main grapevine disease not only in China but also in other grapevine-growing regions worldwide. The disease symptoms appear primarily on the fruit tissues as well as on stems and leaves from 3 to 6 days after the infection [2]. Coniella diplodiella obtains nutrients from infected tissues and eventually decomposes these tissues; however, the molecular mechanism underlying the defense against $C$. diplodiella is not yet clear. We found that WRKY gene family members were induced in grapevines under white rot and salicylic acid (SA) stress, and 16 WRKY genes were upregulated both by white rot pathogenic bacteria and SA; however, the resistance mechanism to $C$. diplodiella remained unknown [3].

The WRKY transcription factors comprise a large family of regulatory proteins and have been implicated in the defense against pathogens in plants [4]. The over-expression of two grapevine WRKY genes, $V v W R K Y 1$ and $V v W R K Y 2$, conferred enhanced resistance against fungal pathogens in transgenic tobacco plants [5]. VvWRKY53 may play a role in eliciting resistance response during the early stage of infection by powdery mildew. It appears to share similar inoculation response with $V v W R K Y 1$, as reported previously [6, 7], whereas knockout of $V v W R K Y 52$ increased grapevine resistance to Botrytis cinerea [8]. $V v W R K Y 33$ can confer resistance to oomycete pathogens when it transiently expressed in leaves [9]. The ectopic expression of $V v W R K Y 11$ provides higher tolerance to water stress induced by mannitol in Arabidopsis [10]. The VpWRKY1, VpWRKY2, VpWRKY3, and VlWRKY48 and VlWRKY3 genes isolated from $V$. pseudoreticulata and $V$. labrusca $\times V$. vinifera cv. 'Kyoho', respectively, enhanced the resistance of these grapevines to biotic and abiotic stresses [11-15]. The AtWRKY53 gene of Arabidopsis, orthologous to $V v W R K Y 53$, was rapidly induced under drought stress [14] and positively regulated basal resistance to Pseudomonas syringae pv. tomato DC3000 (PstDC3000) in combination with AtWRKY46 and AtWRKY70 [15]. The tomato gene orthologous to AtWRKY53, SlWRKY53, confers resistance to tomato yellow leaf curl virus [16].
To ward off tenacious pathogens, plants have developed a vast array of immune responses. Plants, including Vitis species, exhibit different resistance levels depending on their different immune mechanisms. In contrast to $V$. vinifera cultivars, clones of wild grapevine species exhibit high levels of resistance [2] and are used as parental plants to map the major quantitative trait loci of resistance genes $[17,18]$. Breeders can introgress these resistance genes into $V$. vinifera-based cultivars, and conventional breeding has led to the development of some interspecific hybrids that are resistant to fungal diseases. However, this process is long and inefficient. Further breeding programs are required to develop disease-resistant table and wine grapevines that also have high grape berry quality. Such breeding processes might be remarkably accelerated by the availability of grapevine genome sequences [19] and marker-assisted selection [20].

Of the approximately 70 Vitis species worldwide, 38 have originated in China [21]. Chinese wild grapevines are very important germplasms for breeding new cultivars as they possess resistance genes and special resistance mechanisms [22]. We collected 500 accessions from 20 Chinese wild grapevine species and maintained them in a germplasm repository. From this collection, the accession Vitis davidii 0940 showed the highest level of resistance to white rot disease in in vitro analyses [23]. However, the genes associated with the resistance trait have not yet been identified in this grapevine accession. Resistance genes are often induced by pathogen infection in resistant plants [24, 25]. The expression of these genes might be considerably weaker or even absent in susceptible plants. Resistance genes can be identified as differentially expressed genes (DEGs) by conducting comparative analysis of the transcriptomes of resistant and susceptible plants after infection.

In this study, we aimed to identify candidate resistance genes in Vitis davidii by comparing its transcriptome with that of $V$. vinifera. We found that the expression of 20 defense-related genes was induced in $V$. davidii, but not in $V$. vinifera tissues at the early stage of $C$. diplodiella infection. One of these genes, $V d W R K Y 53$, was confirmed to confer resistance to a wide range of pathogens, including C. diplodiella, PstDC3000, and Golovinomyces cichoracearum (powdery mildew of Arabidopsis) when it was over-expressed in transgenic Arabidopsis plants.

\section{Methods}

\section{Observation of the microstructure and ultrastructure of} grapevine leaves

Leaf tissues $\left(0.25 \mathrm{~cm}^{2}\right)$ were collected from the middle of five healthy mature leaves from $V$. vinifera 'Manicure Finger' (VIV) and V. davidii accession 0940 (VID) and fixed in formalin-acetic acid-alcohol fixative. The 
samples were then embedded in paraffin and cut into $10-\mu \mathrm{m}$-thick sections, stained with hematoxylin, examined under a Leica DMi1-PH1 microscope (Leica Camera AG, Wetzlar, Germany), and photographed using an Olympus BX51 camera (Olympus Corp., Tokyo, Japan). Leaf ultrastructure was observed, and images were captured using a HITACHI 7000 (Hitachi Ltd., Tokyo, Japan) transmission electron microscope (TEM) by using the method described by Lighezan et al. [26]

\section{Trypan blue staining}

To visualize microscopic lesions, leaves were stained using the method described by Vogel and Somerville [27] with slight modification. Grape leaves were cut into $1 \mathrm{~cm}^{2}$ segments, placed in $50-\mathrm{mL}$ conical bottles, and vacuum-infiltrated twice in a solution of phenol, lactic acid, glycerol, and water (1:1:1:1) containing $250 \mathrm{mg} / \mathrm{mL}$ trypan blue. The conical bottles were then placed in a boiling water bath for $2 \mathrm{~min}$ and allowed to cool for $1 \mathrm{~h}$. The leaves were de-stained in the 1:1:1:1 solution for $1 \mathrm{~h}$ and examined under bright-field microscopy.

\section{Plant materials and pathogen inoculation treatments on grapevine}

For RNA-sequencing (RNA-seq) analysis, 2-year-old plants of VIV and VID were grown in a greenhouse at $28{ }^{\circ} \mathrm{C}$ with a 16 -h photoperiod. The plants were inoculated with $C$. diplodiella (strain WR01, from the Institute of Plant Protection, Chinese Academy of Agricultural Sciences) by fixing four mycelium gelose discs (diameter $=2 \mathrm{~mm}$ ) on each leaf using small pins, and covering each leaf with a plastic bag to maintain the moisture of the gelose disks during the entire infection period. The mycelium gelose discs were prepared from a $C$. diplodiella culture grown at $28^{\circ} \mathrm{C}$ on potato dextrose agar medium. Leaf samples (plugged around the infection spot) were collected at 0,12 , and $36 \mathrm{~h}$ post inoculation (hpi); each treatment had three independent biological replicates and three mock-infected replicates. The samples were immediately frozen in liquid nitrogen and stored at -80 ${ }^{\circ} \mathrm{C}$. Each sample consisted of pooled specimens from the replicates within each treatment.

\section{RNA extraction, library construction, and RNA-seq}

For RNA-seq library construction, total RNA was extracted from three biological replicates and three mocks at one time point by using the Total RNA Extraction Kit (BioFlux, Tokyo, Japan). The infected samples named $V I V 1, V I V 2, V I V 3$, for $V I V$ and VID1, VID2, and VID3 for $V I D$ were collected at 0,12 , and 36 hpi. The RNA quality and purity were checked on $1 \%$ agarose gels by using a NanoPhotometer spectrophotometer (Implen $\mathrm{GmbH}$, München, Germany).
Sequencing libraries were generated using $3 \mu \mathrm{g}$ of RNA per sample as input material and the NEB Next ${ }^{\circ}$ Ultra $^{\text {tix }}$ RNA Library Prep Kit (NEB, Ipswich, MA, USA) for Illumina sequencing (Illumina Inc., San Diego, CA, USA). Index codes were added to each sample to tag the sequences. The index-coded samples were clustered on a cBot Cluster Generation System by using the TruSeq PE Cluster Kit v3-cBot-HS (Illumina), following the manufacturer's instructions. After the clusters were generated, the libraries were sequenced by Novogene (Beijing, China) on an Illumina HiSeq 2000 platform to generate $100 \mathrm{bp}$ paired-end reads.

\section{Data assembly and analyses}

Clean data (clean reads) were obtained by removing the adapter sequences in the reads. Simultaneously, the Q20, Q30, and GC contents of the clean reads were calculated. All downstream analyses were performed using high-quality clean data.

Reference genome and gene model annotation files were downloaded from the genome website (http:// plants.ensembl.org/Vitis_vinifera). An index of the reference genome was generated using bowtie v2.0.6 (https://sourceforge.net/projects/bowtie-bio/files/ bowtie2/2.1.0/) and paired-end clean reads were aligned to the reference genome by using TopHat v2.0.9 (https://ccb.jhu.edu/software/tophat/index. shtml). The number of reads mapped to each gene was counted using HTSeq v0.5.4p3 (https://pypi. python.org/pypi/HTSeq/0.5.4p3). In addition, the reads per kilobase of transcript per million mapped reads (RPKM) of each gene was calculated based on the length of the gene transcript, the reads mapped to the gene, and the total number of mapped reads [28] The differential expression of each gene under two conditions (infected and non-infected) was analyzed using the DEGseq R package (1.12.0) [29]. The data were analyzed by subtracting each treatment dataset from the corresponding mock dataset. A corrected $P$-value of 0.001 and $\log _{2}$ (fold change) of 1 were set as the thresholds for determining significant differentially expressed genes (DEGs).

\section{Gene co-expression analysis}

Gene co-expression network analysis was performed for each RNA-seq library to identify genes with similar expression patterns in each experimental sample, according to the methods described by J Gillis, followed by a search for resistance-related pathways and genes [30]. The weighted correlation network analysis method was also used for detecting clusters (modules) of highly correlated genes [31]. We subjected the best WGCNA 
results to $\mathrm{MeV} K$-means analysis (http://www.tm4.org/ mev.html) by setting the cluster number to $50(K=50)$.

\section{Annotation and functional classification}

Gene Ontology (GO) enrichment analysis of the DEGs was implemented using the GO seq R package (http:// www.bioconductor.org/packages/release/bioc/html/ goseq.html), in which gene length bias was corrected. The GO terms with corrected $P$-values $<0.05$ were considered significantly enriched in the DEGs. The KOBAS software (http://kobas.cbi.pku.edu.cn/) was used to test the statistical enrichment of the DEGs in the Kyoto Encyclopedia of Genes and Genomes (KEGG) pathways. Putative gene functions were assigned using a set of sequential basic local alignment search tool (BLAST) searches of all the assembled unigenes against sequences in the Ensembl Plants (http://plants.ensembl.org/Vitis vinifera) database of non-redundant proteins and nucleotides $(\mathrm{Nr})$, the Swiss-Prot protein (UniProt) database, the GO database, the Cluster of Orthologous Groups (COGs) database, and the KEGG database.

The full-length amino acid sequence (listed in Additiopnal file S4) and neighbor joining (NJ) method in Clustal X version 1.83 and MEGA version 5.0 (https:// mega.software.informer.com/5.0/) were used.

\section{Quantitative real-time PCR}

Total RNA samples of grapevines and Arabidopsis were extracted using the improved sodium dodecyl sulfate/ phenol method described by Ulker [32]. The PCR primers used for the reference genes (EF1r in grapevine and AtSAND At2g28390 in Arabidopsis) [33] and the test genes are listed in Additional file 1: Table S1. The PCRs were conducted using three biological and three technical replicates for each gene in a LightCycler ${ }^{\circ} 480$ (Roche Diagnostics, Basel, Switzerland). The relative expression levels of the genes were calculated using the $2^{-\triangle \Delta \mathrm{ct}}$ method $[34,35]$.

\section{Vector construction and Arabidopsis transformation}

The full-length cDNA of $V d W R K Y 53$ was amplified using PCR and cloned into the BglII/BstE2 site of the $35 \mathrm{~S}$ promoter in a sense orientation in the binary plasmid pCAMBIA1301 to form the plasmid pCAMBIA1301-VdWRKY53 (pGW53). This new plasmid was verified by sequencing and then introduced into Agrobacterium tumefaciens GV3101 cells for Arabidopsis transformation through the floral dipping method [36, 37].

\section{Pathogenic fungus/bacterium inoculation of Arabidopsis} Homozygous transgenic Arabidopsis plants were used for pathogen inoculation. They were identified from three independent transgenic lines by using hygromycin antibiotic selection and grown to the T3 generation. If $100 \%$ of the T3 plants were hygromycin resistant, the T2 plants were considered as homozygous transgenic plants, and their seeds were re-sown directly into soil without hygromycin selection to generate T3 plants for pathogen inoculation. Coniella diplodiella was inoculated on wild-type (Columbia, Col) and T3 homozygous transgenic (GW53) Arabidopsis plants grown in a chamber at $25{ }^{\circ} \mathrm{C}$ with a 12-h photoperiod and light intensity of $100 \mu \mathrm{mol} \mathrm{m}^{-2} \mathrm{~s}^{-1}$. The powdery mildew (G. cichoracearum) isolate UCSC1 was cultured on the Arabidopsis phytoalexin cichoracent 4 (pad4) mutant plants. Powdery mildew inoculation of Arabidopsis was performed as previously described [38]. The bacterial strain PstDC3000 was grown in Luria-Bertani liquid medium [39] and inoculated by using the method of Melotto et al. [40].

\section{Results}

Anatomical structure and disease symptoms of grapevine leaves

Vitis davidii is an important wild grapevine species that grows in 10 provinces of China. In our previous studies, $V I D$ showed the highest level of resistance among all grapevines tested [23, 41]. In the present study, anatomical structure analysis revealed that the leaves of VID were not significantly different from those of $V I V$ in thickness, including the thickness of the palisade, spongy tissues, and upper and lower epidermis (Table 1, Fig. 1a). Except for the higher number of chloroplasts in the palisade of VID than in the palisade of VIV (Fig. 1a), which is important for photosynthesis, VID had a similar leaf structure to $V I V$. This result suggested that the differences in disease resistance between VID and VIV are likely related to genetic factors and not to anatomic features.

Table 1 Comparison of leaf tissue thickness between the two Vitis species

\begin{tabular}{llllll}
\hline Species & $\begin{array}{l}\text { Leaf thickness } \\
(\mu \mathrm{m})\end{array}$ & $\begin{array}{l}\text { Upper epidermis thickness } \\
(\mu \mathrm{m})\end{array}$ & $\begin{array}{l}\text { Palisade tissue thickness } \\
(\mu \mathrm{m})\end{array}$ & $\begin{array}{l}\text { Spongy tissue thickness } \\
(\mu \mathrm{m})\end{array}$ & $\begin{array}{l}\text { Lower epidermis thickness } \\
(\mu \mathrm{m})\end{array}$ \\
\hline $\begin{array}{l}\text { Vitis } \\
\text { davidii }\end{array}$ & $91.13 \pm 7.48^{\mathrm{a}}$ & $12.43 \pm 2.15^{\mathrm{a}}$ & $36.44 \pm 4.32^{\mathrm{a}}$ & $36.33 \pm 7.70^{\mathrm{a}}$ & $7.87 \pm 1.72^{\mathrm{a}}$ \\
$\begin{array}{l}\text { Vitis } \\
\text { vinifera }\end{array}$ & $112.78 \pm 18.50^{\mathrm{a}}$ & $12.56 \pm 2.82^{\mathrm{a}}$ & $42.75 \pm 8.53^{\mathrm{a}}$ & $48.98 \pm 8.49^{\mathrm{a}}$ & $9.43 \pm 1.84^{\mathrm{a}}$
\end{tabular}

Data are the mean $\pm S D, n=12$. Significant differences were assessed using analysis of variance 


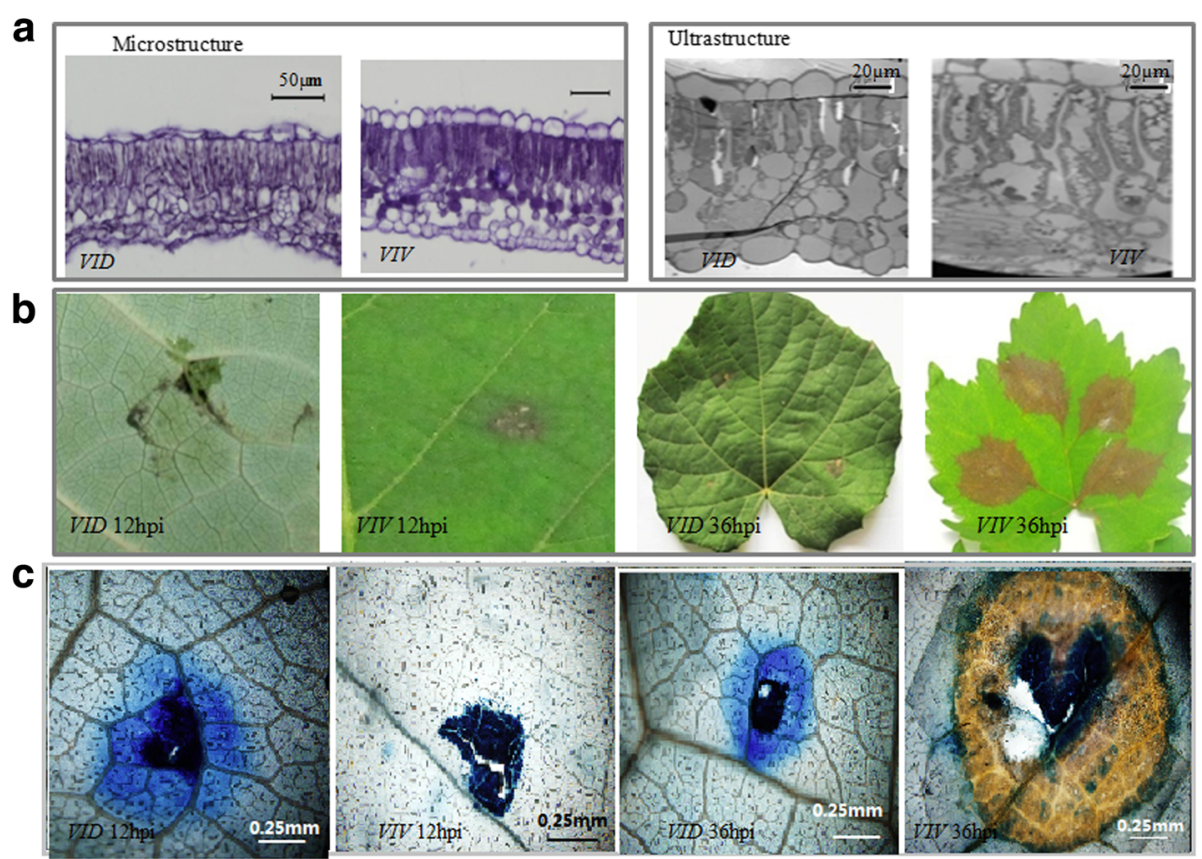

Fig. 1 Vitis leaf structure and symptoms of Coniella diplodiella infection. a Anatomical structure of Vitis vinifera cv. Manicure Finger (VIV) and Vitis davidii accession 0940 (VID). Leaf samples were collected from 2-week-old leaves at 3-4 positions on a branch. At the microstructure level, the leaf thickness, upper epidermis thickness, palisade tissue thickness, spongy tissue thickness, and lower epidermis thickness were not significantly different between VID and VIV. At the ultrastructure level, VID had more chloroplasts in the palisade tissue than in VIV. b Symptoms in VID and VIV after C. diplodiella infection. Typical hypersensitive response (HR) symptoms were observed in VID, but not in VIV at $12 \mathrm{~h}$ post-infection (hpi) and 36 hpi

After infection with $C$. diplodiella, the disease symptoms were weaker on VID leaves than on VIV leaves at $12 \mathrm{hpi}$. After trypan blue staining, at 12 and $36 \mathrm{hpi}$, the symptoms on VID leaves developed into a typical hypersensitive response (HR), showing cell death at the infection site and limited spreading of the pathogen, but the symptoms on VIV leaves developed into typical grapevine white rot disease (Fig. 1b, c), with no HR cell death. Considering that disease development occurs between 12 and $36 \mathrm{hpi}$, we selected these two time points for transcriptome comparison with that at $0 \mathrm{hpi}$.

\section{RNA sequencing analysis}

Approximately 433 million reads were generated from the six libraries (VIV1,VIV2,VIV3,VID1,VID2, and VID3), prepared from the leaf tissues collected at 0,12 , and $36 \mathrm{hpi}$ for comparing the transcript levels of VID and VIV in response to $C$. diplodiella infection. These reads contained 42.32 Giga-bases $(\mathrm{Gb})$ of cDNA (Table 2). More than $96 \%$ of these reads had high quality $(\mathrm{Q}>20)$ and, therefore, they were selected for further analyses. Of the clean reads, $77-88 \%$ were mapped to the $V$. vinifera reference genome (http://plants.ensembl. org/Vitis_vinifera) [20]. For each library, the reads were mapped to approximately 23,000-25,000 genes, of which approximately 1000 were novel genes that were not annotated in the grapevine reference genome (Table 2).

\section{Identification of DEGs}

According to the DEGseq, 12,976 genes had RPKM $>1$ and were, therefore, selected for DEG analysis. The number of DEGs between the resistant (VID) and susceptible $(V I V)$ grapevine plants were analyzed at each time point after $C$. diplodiella inoculation.

A total of 7073 transcripts, differing in expression between the two grapevines, were induced. Two hundred and fifty-six transcripts specifically expressed in VID were from novel genes that were not identified in the reference genome (http://plants.ensembl.org/Vitis_vinifera). This could be due to the large genetic distance between VID and the grapevine species used to generate the reference genome. Overall, more DEGs were found in the resistant genotype VID than in the susceptible genotype $V I V$. One-hundred and seventy-four DEGs (24 up-regulated and 150 down-regulated) were more expressed in VID than in VIV at 12 and $36 \mathrm{hpi}$, while the expression of 240 more DEGs (49 up-regulated and 191 down-regulated) changed more in VID than in VIV at 12 hpi, and that of 415 DEGs (199 up-regulated and 216 down-regulated) changed more in VID than in VIV at 36 hpi (Fig. 2). 
Table 2 Summary of the mean transcriptome data

\begin{tabular}{lllllll}
\hline & VIV1 & VIV2 & VIV3 & VID1 & VID2 & VID3 \\
\hline Total reads (× 1000) & 76,192 & 76,999 & 67,696 & 67,447 & 71,886 & 73,179 \\
Base number (Gb) & 7.62 & 6.7 & 6.76 & 6.74 & 7.18 & 7.32 \\
High-quality reads (\%) & 98.1 & 96.48 & 97.97 & 96.31 & 98.02 & 96.46 \\
Mapped reads (\%) & 88.01 & 87.27 & 87.43 & 77.33 & 76.96 & 77.14 \\
Number of transcripts & 23,621 & 24,301 & 24,407 & 23,441 & 25,537 & 24,018 \\
Number of novel transcripts & 961 & 971 & 997 & 938 & 1020 & 957 \\
\hline
\end{tabular}

All DEGs were annotated by searching multiple databases, including COG, GO, KEGG, Swiss-Prot, and nr (Table 3) [42-44]. To determine pathways containing DEGs between the susceptible $V I V$ and resistant $V I D$, we analyzed the KEGG pathways in detail. We detected DEGs in 118 pathways, but two pathways (brassinosteroid biosynthesis, and cutin, suberine, and wax biosynthesis) contained no DEGs. Differences in gene expression at two time points after pathogen infection in $V I V$ and VID were examined, and DEGs were identified by pairwise comparisons of the six treatments (Additional file 2: Table S2 and Additional file 3: Table S3).

We statistically analyzed the number of important functional genes that were induced, including genes related to cell wall, energy, hormone, E3, RNA, transcription factor, and amino acid biosynthesis, stress response, growth, resistance, and basic functions, and new genes (Fig. 3). Among these, 374 genes related to cell wall, energy, hormone, and transcription factor biosynthesis and resistance were induced in VID2 but not in VIV2. In contrast, 28 genes involved in the same processes were induced in VIV3 but not in VID3.

\section{Identification of candidate resistant genes}

We focused on plant-pathogen interaction pathways to identify candidate resistant genes. These pathways included cell wall genes, leucine-rich repeat (LRR) receptor-like genes, WRKY genes, and pathogenesis-

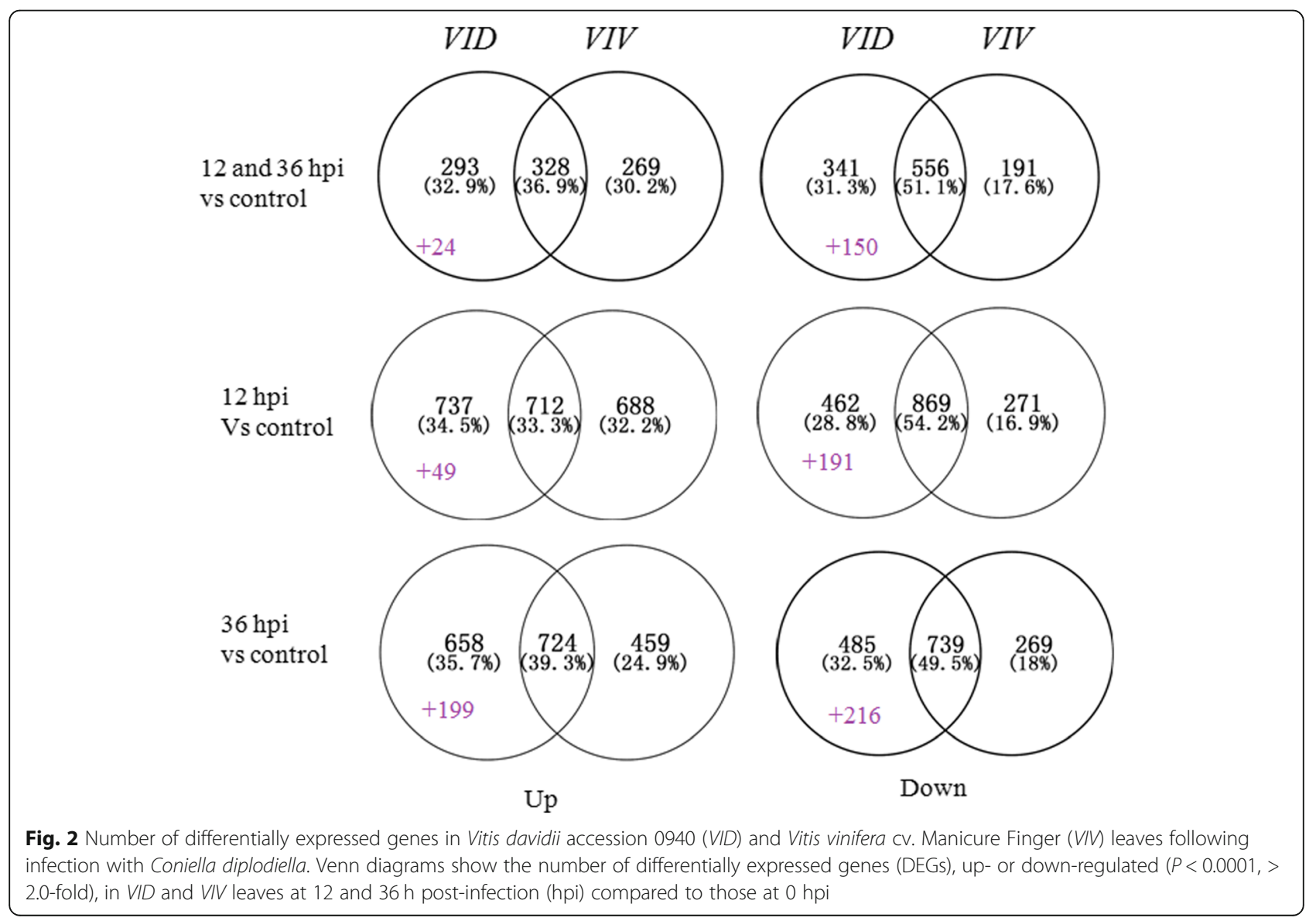


Table 3 Annotation of the differentially expressed genes (DEGs) from six treatments

\begin{tabular}{lllllll}
\hline DEG Set & Annotated & COG & GO & KEGG & Swiss-Prot & $\mathrm{nr}$ \\
\hline VID2_vs_VID1 & 3952 & 1617 & 3517 & 675 & 2997 & 3952 \\
VID3_Vs_VID1 & 4025 & 1657 & 3594 & 677 & 3114 & 4025 \\
VIV2_Vs_VIV1 & 3925 & 1664 & 3506 & 656 & 3031 & 3925 \\
VIV3_Vs_VIV1 & 3869 & 1572 & 3455 & 636 & 2986 & 3869 \\
\hline
\end{tabular}

related (PR) genes. All transcripts in these pathways were classified into four co-expression groups by using WGCNA. One of these groups was further divided into 50 co-expression subclusters $(K=50)$, by using software $\mathrm{MeV}$ in $K$-means analysis (http://www.tm4.org/), based on the molecular function and RPKM value of the genes. In one of these subclusters, K03, the transcript levels of 152 genes were higher in VID than in VIV at 0 and 12 hpi, whereas their transcript levels were reduced at 36 hpi compared to those at 0 and 36 hpi in both VIV and VID (Fig. 4, Additional file 4: Table S4).

From subcluster K03, 20 candidate resistant genes from the SA signaling pathway were selected because their expression pattern was highly correlated with the resistance response. Their expression levels in the six libraries obtained for the two grapevine species are listed in Table 4. The selected candidate genes showed RPKM $>1$ and $\log _{2}$ (fold change) $>2$. These 20 genes included two wall-associated receptor kinase genes, five $L R R$ receptor-like serine/threonine-protein kinase genes, eleven WRKY transcription factor genes, and two PR protein-like genes. The expression pattern of these candidate genes was confirmed by qRT-PCR analyses by using the RNA extracted at 12 hpi. Nineteen genes that showed a higher RPKM value in VID than in VIV were confirmed to have higher expression level in VID than in $V I V$ at 12 hpi. Only two genes (VIT_18s0041g00020 and VIT_07s0005g01710) showed an opposite trend between RNA-seq and qRT-PCR analyses (Fig. 5).

\section{Functional verification of the candidate gene WRKY53}

In higher plants, WRKY genes play various roles. Accumulating evidence indicates that WRKY transcription factors are involved in the responses to biotic stresses as well as in plant development [45-48]. The WRKY

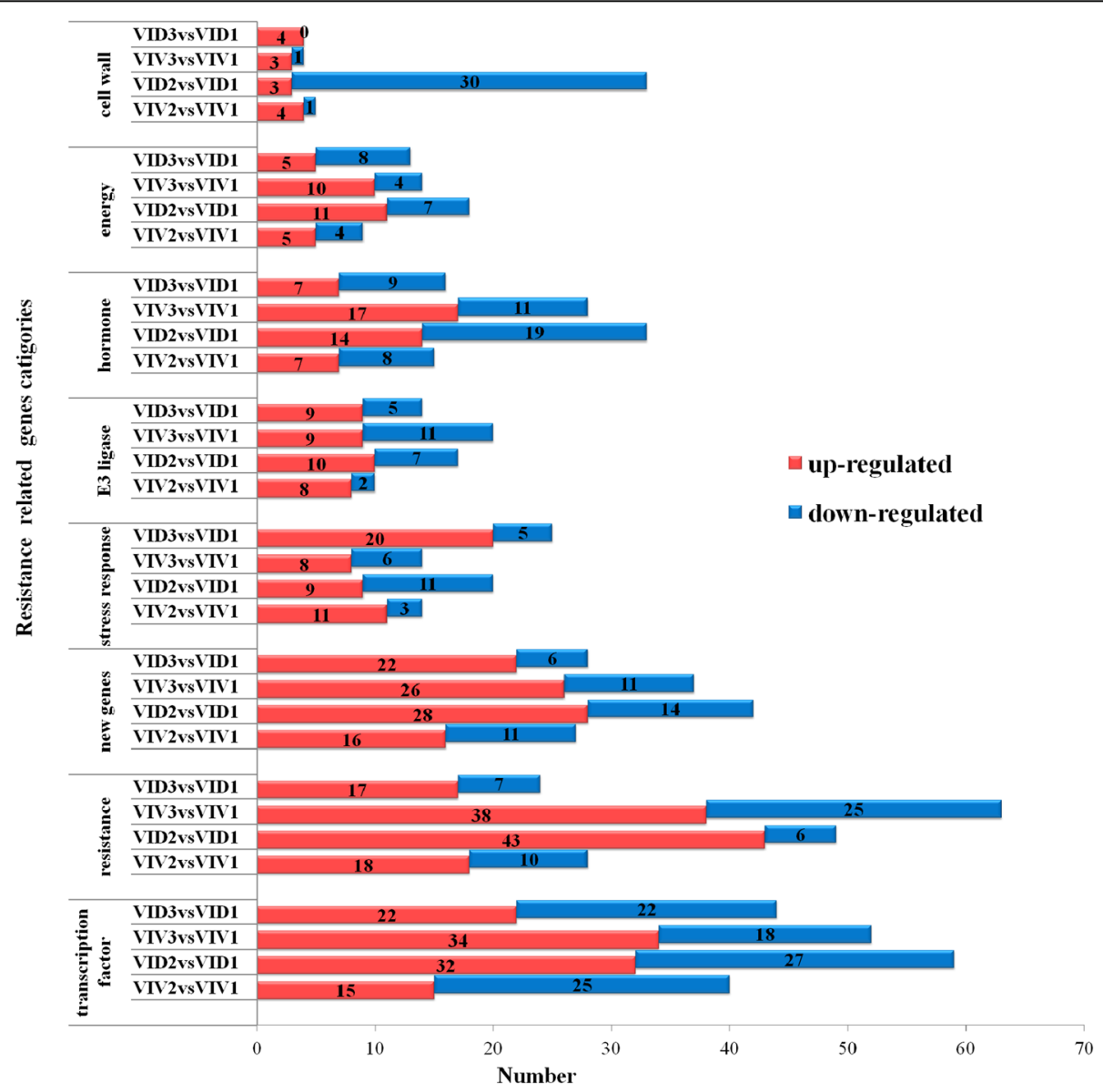

Fig. 3 Important function of differentially expressed genes in Vitis davidii accession 0940 (VID) and Vitis vinifera cv. Manicure Finger (VIV) following infection with Coniella diplodiella 


\section{Subcluster $03 \log _{2}$ median centered rpkm matrix 152 transcripts}

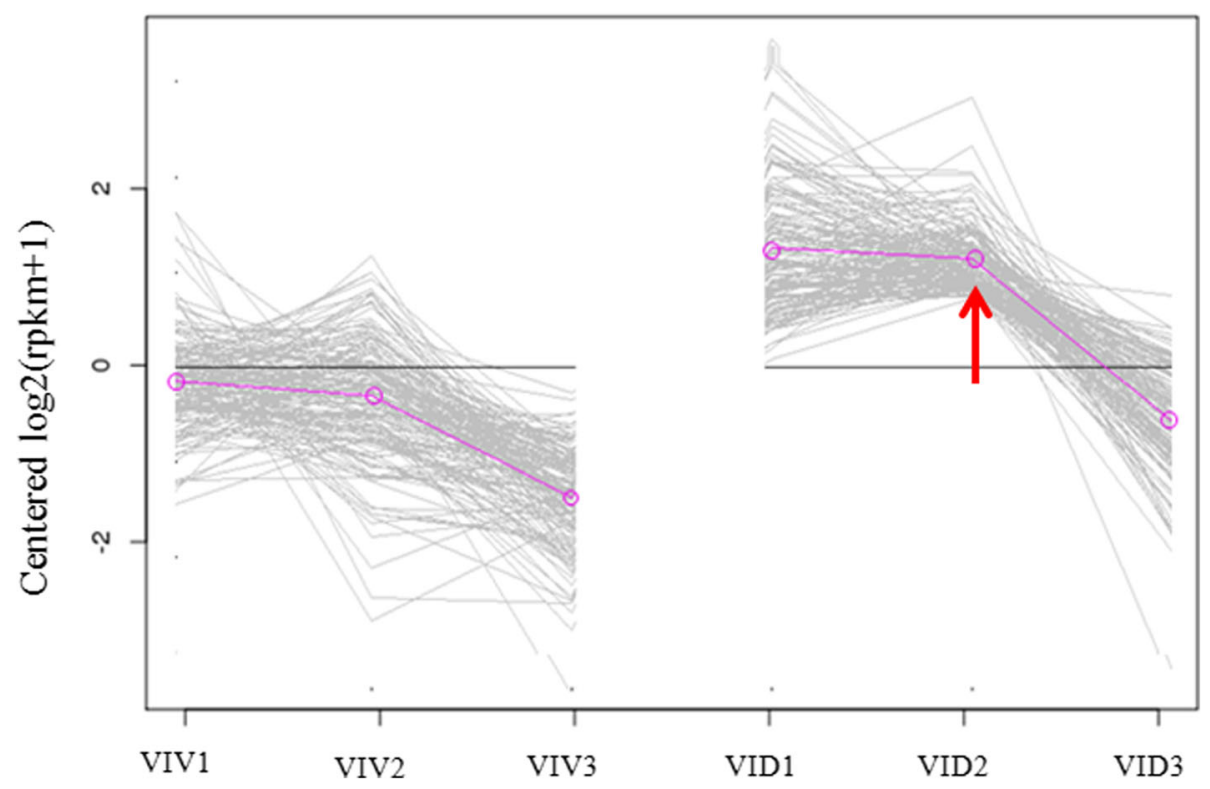

Fig. 4 The subcluster K03 from K-means co-expression analysis. All differentially expressed genes (DEGs) were divided into 50 co-expression subclusters $(K=50)$ by using the MeV K-means analysis. In subcluster K03, 152 DEGs showed significant co-expression tendency at $12 \mathrm{~h}$ post-infection

Table 4 Defense-related candidate genes classified in the co-expression subcluster K03

\begin{tabular}{|c|c|c|c|c|c|c|c|}
\hline \multirow[t]{2}{*}{ Gene ID } & \multirow[t]{2}{*}{ Gene function } & \multirow[b]{2}{*}{ VIV1 } & \multicolumn{5}{|c|}{ RPKM value } \\
\hline & & & DA1 & VIV2 & DA2 & VIV3 & DA3 \\
\hline VIT_18s0041g00020 & Wall-associated receptor kinase 2 & 9.69 & 22.35 & 13.35 & 16.12 & 10.79 & 76.36 \\
\hline VIT_18s0001g11620 & Wall-associated receptor kinase 2 & 0.42 & 5.24 & 2.48 & 19.85 & 0.60 & 1.52 \\
\hline VIT_12s0035g00070 & LRR receptor-like serine/ threonine-protein kinase & 1.55 & 16.89 & 2.86 & 53.64 & 1.57 & 54.97 \\
\hline VIT_12s0055g00580 & LRR receptor-like serine/threonine-protein kinase & 1.35 & 5.42 & 2.55 & 24.08 & 1.84 & 5.52 \\
\hline VIT_12s0035g00180 & LRR receptor-like serine/threonine-protein kinase & 0.75 & 1.25 & 0.81 & 33.93 & 1.07 & 2.52 \\
\hline Vitis_vinifera_newGene_4892 & LRR receptor-like serine/threonine-protein kinase & 0.90 & 1.79 & 0.24 & 8.41 & 0.05 & 1.22 \\
\hline Vitis_vinifera_newGene_4928 & LRR receptor-like serine/threonine-protein kinase & 1.67 & 10.70 & 11.78 & 27.30 & 0.12 & 5.41 \\
\hline VIT_07s0005g02570 & WRKY transcription factor & 20.39 & 34.65 & 128.83 & 186.78 & 26.54 & 36.92 \\
\hline VIT_16s0050g02510 & WRKY transcription factor & 15.66 & 21.43 & 36.74 & 103.31 & 23.85 & 24.72 \\
\hline VIT_07s0005g01710 & WRKY transcription factor & 6.56 & 6.81 & 7.35 & 20.64 & 3.61 & 3.84 \\
\hline VIT_01s0010g03930 & WRKY transcription factor & 4.07 & 22.10 & 32.43 & 96.59 & 5.71 & 21.80 \\
\hline VIT_17s0000g01280 & WRKY transcription factor & 0.31 & 2.62 & 3.68 & 10.42 & 0.44 & 9.98 \\
\hline VIT_19s0090g00840 & WRKY transcription factor & 0.44 & 9.93 & 4.63 & 68.05 & 0.30 & 2.17 \\
\hline VIT_10s0003g02810 & WRKY transcription factor & 1.37 & 25.96 & 3.77 & 27.71 & 1.47 & 4.30 \\
\hline VIT_01s0026g01730 & WRKY transcription factor & 1.72 & 5.47 & 14.58 & 27.03 & 2.9 & 2.76 \\
\hline VIT_05s0077g00730 & WRKY transcription factor & 13.33 & 75.25 & 26.90 & 109.90 & 7.25 & 22.38 \\
\hline VIT_10s0003g01600 & WRKY transcription factor & 11.80 & 47.38 & 76.53 & 104.56 & 17.11 & 46.80 \\
\hline VIT_02s0025g00420 & WRKY transcription factor & 0.19 & 0.46 & 2.59 & 13.44 & 0.62 & 1.64 \\
\hline VIT_11s0052g01620 & Pathogenesis-related protein PR-1 & 2.35 & 0.97 & 0.91 & 18.12 & 3.85 & 7.39 \\
\hline VIT_14s0081g00020 & Pathogenesis-related protein PR-1 & 5.25 & 17.21 & 4.56 & 69.54 & 0.86 & 4.87 \\
\hline
\end{tabular}




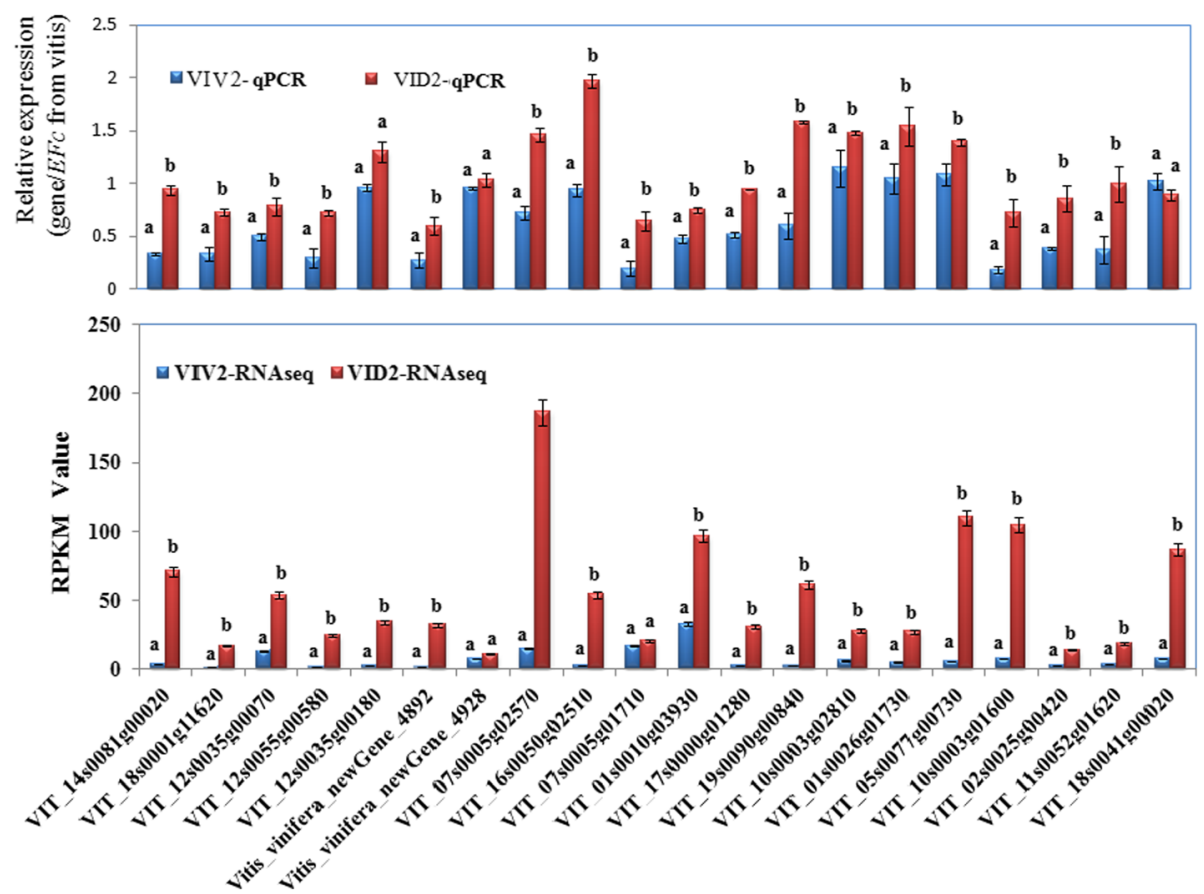

Fig. 5 Comparison between RNA sequencing (RNA-seq) and quantitative real-time PCR (qRT-PCR) results for 20 defense-related candidate genes. Based on RNA-seq analysis, 152 DEGs were clustered in K03. Twenty defense-related genes in K03 that showed significant differential expression at $12 \mathrm{~h}$ post-infection were further analyzed using qRT-PCR

proteins constitute a large family of transcription factors [44], and some are potentially involved in the regulation of the transcriptional reprogramming responsible for plant immune responses [49]. In the present study, 11 WRKY genes were identified as candidate resistance genes from VID because their expression was positively correlated with resistance to $C$. diplodiella.

The gene VIT_16s0050g02510 (gene ID in the V. vinifera Pinot Noir PN40024 reference genome) was selected for further characterization because it was grouped in the subcluster $\mathrm{K} 03$ during co-expression analysis and showed a higher expression level in VID than in VIV at 12 hpi (2.8 fold change; Figs. 4 and 5). The cDNA of this gene was cloned from VID and named as VdWRKY53. Its cDNA sequence was deposited in GenBank (accession no. KY124243) and it was annotated to WRKY53 based on the grapevine gene nomenclature system [50]. This gene belongs to Group III subfamily of the WRKY family. In plants, the members of this subfamily are considered the most evolutionarily advanced and adaptable and to have coevolved with disease resistance genes [51]. The VdWRKY53 gene showed higher expression in VID than in VIV even at 0 hpi. The RPKM value of VdWRKY53 was 109.9 in response to $C$. diplodiella infection at approximately $12 \mathrm{dpi}$ (Table 4). In the phylogenetic analysis performed here, VdWRKY53 was found to be closely related to VvWRKY30, VvWRKY46, and VvWRKY41 from $V$. vinifera and AtWRKY41 and
AtWRKY53 from Arabidopsis (Fig. 6). We produced Arabidopsis transgenic plants by using the pGW53 construct for over-expressing VdWRKY53 under the control of the CaMV35S promoter. Homozygous transgenic plants were identified from three independent transgenic lines, GW53-1, GW53-2, and GW53-3, by using hygromycin selection and growing them to the T3 generation. Although $V d W R K Y 53$ was expressed in all three transgenic lines, as determined by qRT-PCR, its expression level was approximately three-fold higher than the mRNA level of the Arabidopsis reference gene AtSAND (At2g28390; Fig. 7). A background level of expression detected in the wild-type Arabidopsis Col plants could be the result of non-specific amplification of Arabidopsis genes with homology to the qRT-PCR primers used.

The homozygous transgenic plants and wild-type Arabidopsis Col control plants were infected with $C$. diplodiella, G. cichoracearum, and PstDC3000. After infection with G. cichoracearum, GW53 plants grew normally with green leaves despite the presence of powdery mildew. However, the wild-type Arabidopsis Col plants developed clear disease symptoms, with yellow and even dead leaves. The same result was noted following $C$. diplodiella and PstDC3000 infection (Fig. 8). After inoculation with $G$. cichoracearum, C. diplodiella, and PstDC3000, GW53 plants showed disease symptoms on 5,3 , and $2 \%$ of their leaves, respectively, whereas Col plants showed disease symptoms on 95,97 , and $98 \%$ of 


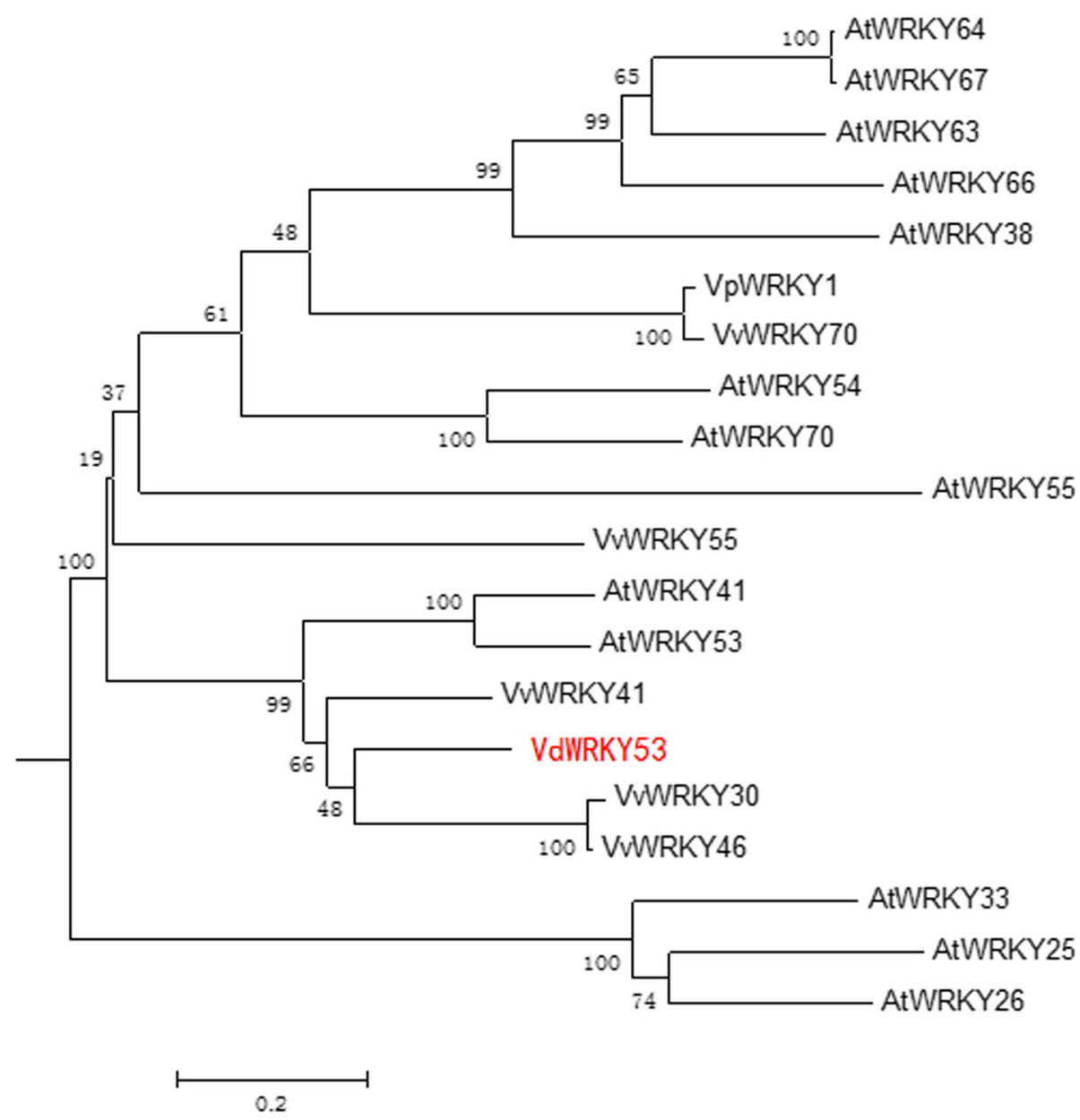

Fig. 6 Phylogenetic relationships among the WRKY transcription factors of Vitis vinifera and Arabidopsis. A phylogenetic tree was constructed using the full-length amino acid sequence (listed in Additional file 4) and neighbor joining (NJ) method in Clustal X version 1.83 and MEGA version 5.0. The scale bar represents 0.2 substitutions per site, and the numbers next to the nodes are bootstrap support values from 1000 replicates

their leaves, respectively (Fig. 9). This indicated that the expression of the grapevine VdWRKY53 gene in Arabidopsis could improve disease resistance.

\section{Discussion}

Grapevine white rot disease is the most severe threat to Vitis species production; in order to identify a germplasm that can be used for research and breeding, we focused on $V$. davidii, which was reported to be a resistant species. We verified the resistance of this germplasm to white rot disease by examining HR lesions using trypan blue staining. The RNA-seq results also showed that more genes were induced in $V$. davidii than in $V$. vinifera, a susceptible species (Fig. 2). However, the expression of important functional genes presented more changes in VID than in VIV; this finding was similar to that noted in $V$. riparia infected with Plasmopara viticola. Further, the same response was found to appear very rapidly after infection in the resistant germplasm $V$. riparia [52]. Co-expression analysis revealed that the K03 cluster included the same resistance pathway as that induced in $V$. riparia; to verify this, we identified the core gene $V d W R K Y 53$, which was the most up-regulated in the cluster. The over-expression of this gene in Arabidopsis increased its resistance to $C$. diplodiella, PstDC3000, and G. cichoracearum.

\section{Rapid response contributes to disease resistance in VID}

The first step of plant defense against pathogens is the cell wall-associated response. Pathogenic microorganisms need to actively penetrate the plant apoplast for accessing intercellular nutrients. The second step is HR, in which cell death surrounding an infection site restricts the growth of pathogens. Ralph Huckelhoven considered HR-associated cell death to be a complex defense that depends on the timing of HR [45]. In this study, VID rapidly showed a typical HR after $C$. diplodiella invasion. The HR and cell death limited pathogen 


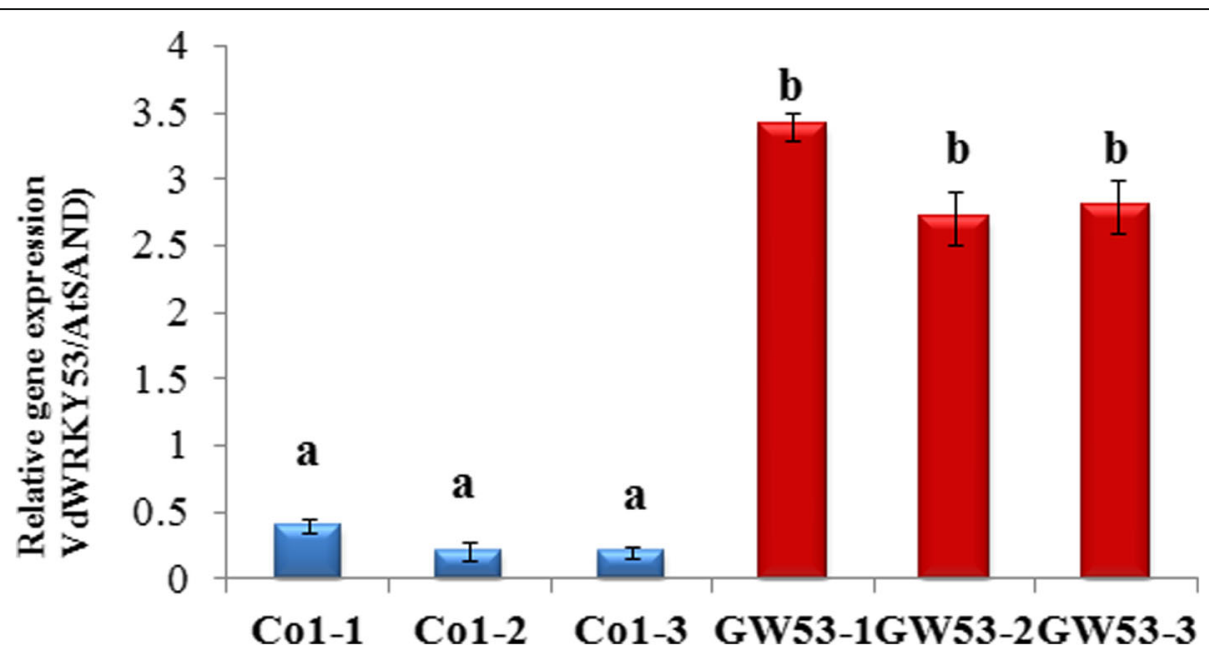

Fig. 7 Quantitative real-time PCR analyses of VdWRKY53 gene expression in wild-type and transgenic Arabidopsis plants. The expression levels of VdWRKY53 in three wild-type (Col-1, Col-2, and Col-3) and three transgenic (GW53-1, GW53-2, and GW53-3) Arabidopsis lines were analyzed before pathogen infection. The error bars represent the standard deviation of three independent analyses

invasion, and then induced the expression of resistance genes in the defense signaling pathways (Fig. 1b, c). The expression of 20 defense-related genes was higher in VID than in VIV at 0 and 12 hpi (Fig. 3). This result indicated that the expression of defense-related genes in VID was a part of the resistance response induced at 12 hpi. This type of response was also observed in other resistant grapevine species such as $V$. riparia after infection with $P$. viticola [38]. This rapid HR response in VID could be induced by perceiving microbial molecules or by surveillance of host cellular intactness, which is a common mechanism in plants. This mechanism has also been observed in $V$. riparia infected with $P$. viticola [52]. A defense response was observed in the resistant species $V I D$, which rapidly recognized the infection signal and activated $\mathrm{HR}$.

\section{Candidate genes contributing to defense in VID}

Detailed pathogen resistance mechanisms have been described in model plant species. They involve complex signaling pathways and a cascade of resistance genes that can be triggered by an elicitor. Plants use pathogen-associated molecular patterns or damage-associated molecular patterns to recognize general elicitors or a
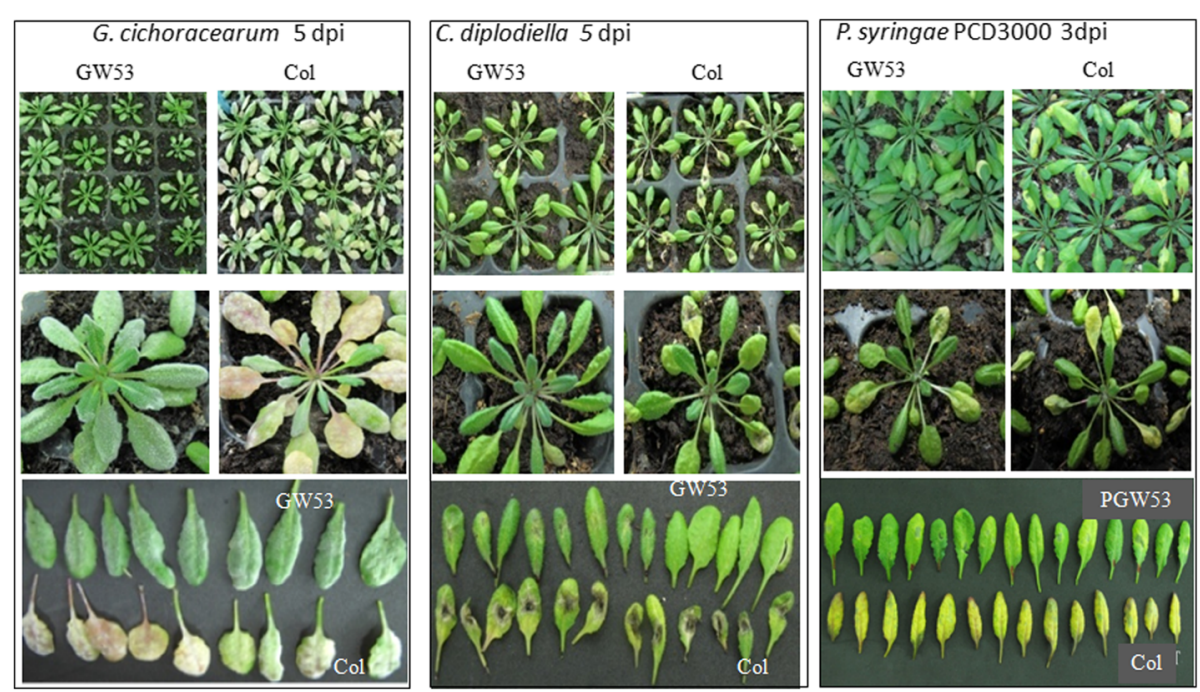

Fig. 8 Transgenic Arabidopsis plants over-expressing VdWRKY53 showed enhanced resistance to pathogens. Homozygous transgenic plants from three different lines were separately infected with Golovinomyces cichoracearum, Coniella diplodiella, and Pseudomonas syringae pv. tomato DC3000. The images show the results of one transgenic line along with wild-type controls post-infection. The plants of other transgenic lines showed similar results 


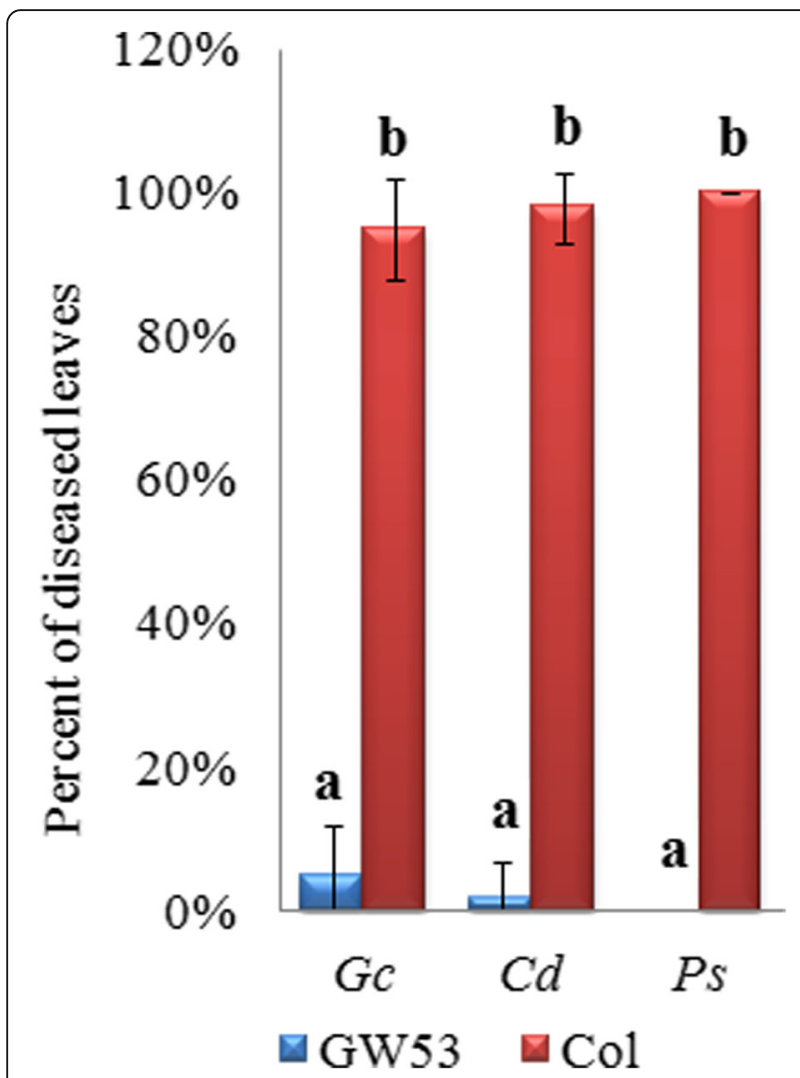

Fig. 9 Percentage of Arabidopsis leaves that were free of symptoms after pathogen infection. Homozygous transgenic plants from three different lines were separately infected with Golovinomyces cichoracearum (Gc), Coniella diplodiella (Cd), and Pseudomonas syringae pv. tomato DC3000 (Ps). Disease symptoms were visually examined on 33 leaves for each line at 5 days post-infection (dpi) for $G c$ and $C d$ and at 3 dpi for Ps. The error bars represent the standard deviations of three transgenic lines or three populations of wild-type control plants

special elicitor, which is similar to the innate immune system in animals [53]. When a fungus infects a plant, an exchange of signals occurs between the pathogen and the plant [54].

Cell wall-associated plant defense is the first and most important barrier in basal resistance. Basal resistance seems to be suppressed by virulent pathogens but boosted in induced and race-specific resistance. In Oryza sativa, OsWAK1 transcripts were significantly induced by Magnaporthe oryzae and played an important role in rice blast disease resistance [55]. In the present study, two wall-associated receptor kinase (WAK) genes (VIT_18s0041g00020 and VIT_18s0001g11620) were selected as candidate resistance genes.

In plant resistance and animal innate immune systems, serine/threonine-rich repeat receptor-like kinases contribute to the detection of non-self molecules [56, 57]. Five receptor kinase genes were selected as candidates, namely, LRR receptor-like serine/threonine protein kinases (VIT_12s0035g00070, VIT_10s0092g00590, VIT_12s0055g00580, Vitis_vinifera_newGene_4892, and Vitis_vinifera_newGene_4928). The downstream phosphorylation of a WRKY transcription factor ultimately led to the activation of defense-related genes and the partial restriction of pathogen growth [58].

Eleven WRKY transcription factors responded to fungal infection in the present study, showing a co-expression pattern in the $\mathrm{K} 03$ subcluster. The $\mathrm{PR}$ proteins are secreted into the defense system during the resistance response. For example, PR-1 has antifungal and antibiotic activity $[56,58-61]$ and, in the present study, two PR-1 genes (VIT_11s0052g01620 and VIT_14s0081g00020) were shown to participate in the defense against pathogen invasion in VID. Plant resistance to diseases might be attributed to specific plant surface and cell wall structures, or HR type self-protection [62]. Our results indicated that the resistance in VID was a HR protection, and many candidate genes in the pathogen-associated molecular pattern pathway associated with HR were activated.

\section{Over-expression of VdWRKY53 improved disease resistance in Arabidopsis}

We cloned the cDNA of VdWRKY53 and ectopically expressed it in Arabidopsis transgenic plants. As expected, VdWRKY53 conferred strong resistance to $C$. diplodiella, PstDC3000, and G. cichoracearum in the transgenic plants. Arabidopsis mutants with loss of AtWRKY53 function showed delayed development of disease symptoms after infection with Ralstonia solanacearum but increased susceptibility toward PstDC3000 [63]. The expression of AtWRKY41 is specifically suppressed by a compatible strain of PstDC3000 in an effector-dependent manner [4]. As VdWRKY53 was classified into the same clade as AtWRKY41 and AtWRKY53, it may play a role in disease resistance. After inoculation with G. cichoracearum, C. diplodiella, and PstDC3000, GW53 plants showed improving disease resistance.

\section{Conclusions}

Innate immune perception triggers both local and systemic responses, allowing a plant to fight off pathogens in a rapid and localized manner and on an extended scale of time and space. The plant defense response to pathogen invasion involves multiple biological processes. Candidate genes from the K03 cluster were co-expressed and classified in the same resistance pathway $[41,49,64$, 65]. Their functions include the recognition of virulence factors, transferring the factor to signaling modules (NB-LRR: the nucleotide binding-leucine rich repeat, NLRs: nucleotide-binding domain and leucine-richrepeat-containing proteins, and LRR: receptor-like kinase), regulation of switch genes (WRKY) by different modules, and activation of the resistance pathway 
response. These processes involve genes belonging to the WAK, LRR, WRKY, and PR gene families. In the present study, 20 genes were identified from these families in a co-expression cluster (K03) that showed an expression pattern induced by the infection of grapevine white rot pathogen in VID at $12 \mathrm{hpi}$. The key gene VdWRKY53 was also found to improve resistance to disease in transgenic Arabidopsis plants. Based on these data, we propose that these 20 candidate genes might contribute to the resistance of VID to grapevine white rot disease. As an important germplasm resource, highly resistant to $C$. diplodiella, VID could be used as a parent for resistance breeding in grapevine.

\section{Additional files}

Additional file 1: Primer sequences used in this study. (DOCX $16 \mathrm{~kb}$ )

Additional file 2: Number of DEGs between $V$. davidii and $V$. vinifera in different KEGG pathways detected at different infection stages. (DOCX $25 \mathrm{~kb}$ )

Additional file 3: Details of the KEGG pathways investigated in this study. (XLSX $122 \mathrm{~kb}$ )

Additional file 4: Details of genes classified in subcluster K03. (XLSX 69 kb)

\section{Abbreviations}

COGs: Cluster of Orthologous Groups; GO: Gene Ontology; HR: Hypersensitive response; KEGG: Kyoto Encyclopedia of Genes and Genomes; Nr: Non-redundant proteins and nucleotides; PR-1: pathogenesis-related protein 1; SA: Salicylic acid; UniProt; Swiss: Prot protein; VI: Vitis davidii accession 0940; VIV: Vitis vinifera 'Manicure Finger'

\section{Acknowledgments}

This work was financially supported by the National Natural Science Foundation of China (No., 31201599), the China Agriculture Research System (CARS-29), the Agricultural Science and Technology Innovation Program (CAAS-ASTIP-2017-ZFRI).

\section{Funding}

No

\section{Availability of data and materials}

The datasets supporting the conclusions of this study are included within the article (and its additional file(s)).

\section{Authors' contributions}

$Z Y$ transformed the target gene and drafted the manuscript: HF analyzed the data; XCF transformed the target gene; JFJ constructed the vector and detected the transgenic plants; $\mathrm{CHL}$ was responsible for plant cultivation and management; ML was in charge of the survey of agronomic traits; JLY revised the manuscript. All authors read and approved the final manuscript.

\section{Ethics approval and consent to participate}

Not applicable.

\section{Consent for publication}

Not applicable.

\section{Competing interests}

The authors declare that they have no competing interests.

\section{Publisher's Note}

Springer Nature remains neutral with regard to jurisdictional claims in published maps and institutional affiliations.

\section{Author details}

${ }^{1}$ Zhengzhou Fruit Research Institute, Chinese Academy of Agriculture Sciences, Zhengzhou 450009, China. ${ }^{2}$ The New Zealand Institute for Plant \& Food Research Limited, Auckland, New Zealand.

Received: 6 November 2018 Accepted: 11 April 2019

Published online: 26 April 2019

\section{References}

1. Alleweldt G, Possingham JV. Progress in grapevine breeding. Theor Appl Genet. 1988;75:669-73.

2. Yuejin $W$, Puchao $H$. Study of white rot disease resistant mechanism in Chinese Vitis wild species. Northern Horticulture. 1988;1:1-5.

3. Zhang Y, Feng J. Identification and characterization of the grape WRKY family. Identification and Characterization of BioMed Research International. 2014;2014:1-14.

4. Pandey SP, Somssich IE. The role of WRKY transcription factors in plant immunity. Plant Physiol. 2009;150:1648-55.

5. Marchive C, Mzid R, Deluc L, Barrieu F, Pirrello J, Gauthier A, et al. Isolation and characterization of a Vitis vinifera transcription factor, VVWRKY1, and its effect on responses to fungal pathogens in transgenic tobacco plants. J Exp Bot. 2007:58:1999-2010.

6. Mzid R, Marchive C, Blancard D, Deluc L, Barrieu F, Corio-Costet MF, et al. Overexpression of $\mathrm{V} V W R K Y 2$ in tobacco enhances broad resistance to necrotrophic fungal pathogens. Physiol Plant. 2007;131:434-47.

7. Guo C, Guo R, Xu X, Gao M, Li X, Song J, Zheng Y, Wang X. Evolution and expression analysis of WRKY gene family in grape. J Exp Bot. 2014;65(6): 1513-28.

8. Wang X, Tu M, Wang D, Liu J, Li Y, Li Z, Wang Y, Wang X. CRISPR/Cas9mediated efficient targeted mutagenesis in grape in the first generation. Plant Biotechnol J. 2018;16:844-55.

9. Merz PR, Moser T, Holl J, Kortekamp A, Buchholz G, Zyprian E, et al. The transcription factor VVWRKY33 is involved in the regulation of grapevine (Vitis vinifera) defense against the oomycete pathogen Plasmopara viticola. Physiol Plant. 2015:153:365-80.

10. Liu H, Yang W, Liu D, Han Y, Zhang A, Li S. Ectopic expression of a grapevine transcription factor VWWRKY11 contributes to osmotic stress tolerance in Arabidopsis. Mol Biol Rep. 2012;38:417-27.

11. Zhu Z, Shi J, Cao J, He M, Wang Y. VpWRKY3, a biotic and abiotic stressrelated transcription factor from the Chinese wild Vitis pseudoreticulata. Plant Cell Rep. 2012;31:2109-20.

12. Sun $Y, Y u$ D. Activated expression of AtWRKY53 negatively regulates drought tolerance by mediating stomatal movement. Plant Cell Rep. 2015: 34, 1295-1306 2015.

13. Hu Y, Dong Q, Yu D. Arabidopsis WRKY46 coordinates with WRKY70 and WRKY53 in basal resistance against pathogen Pseudomonas syringae. Plant Sci. 2012;185:288-97.

14. Guo R, Qiao H, Zhao J, Wang X, Tu M, Guo C, Wan R, Li Z, Wang X. The grape VIWRKY3 gene promotes abiotic and biotic stress tolerance in transgenic Arabidopsis thaliana. Front Plant Sci. 2018:9:545.

15. Zhao J, Zhang X, Guo R, Wang Y, Guo C, Li Z, Chen Z, Gao H, Wang X Over-expression of a grape WRKY transcription factor gene, VIWRKY48, in Arabidopsis thaliana increases disease resistance and drought stress tolerance. Plant Cell Tissue Organ Cult. 2018;132:359-70.

16. Huang Y, Li MY, Wu P, et al. Members of WRKY group III transcription factors are important in TYLCV defense signaling pathway in tomato (Solanum lycopersicum). BMC Genomics. 2016;17(788):2016.

17. Bellin D, Peressotti E, Merdinoglu D, et al. Resistance to Plasmopara viticola in grapevine 'Bianca' is controlled by a major dominant gene causing localised necrosis at the infection site. Theor Appl Genet. 2009;120:163-76.

18. Malacarne G, Vrhovsek U, Zulini L, et al. Resistance to Plasmopara viticola in a grapevine segregating population is associated with stilbenoid accumulation and with specific host transcriptional responses. BMC Plant Biol. 2011;11:1-13.

19. Jaillon O, Aury JM, Noel B, et al. The grapevine genome sequence suggests ancestral hexaploidization in major angiosperm phyla. Nature. 2007:449: 463-7.

20. Costantini L, Battilana J, Lamaj F, Fanizza G, Grando MS. Berry and phenology-related traits in grapevine (Vitis vinifera L.): from quantitative trait loci to underlying genes. BMC Plant Biol. 2008;8:1-17. 
21. Kong Q. Flora of Chinese Grapes. Beijing: China Agricultural Science and Technology Press; 2004. p. 14-7.

22. Feng L, Xiucai F, Chonghuai L, Ying Z, Jianfu J, Min L. Investigation resistance to white rot in grape germplasm resources. China Fruits. 2012;4:72-4 2012.

23. Zhang $Y$, Sun $H$, Fan $X$, Jiang J, Liu C. Identification and evaluation of resistance of Vitis to grape white rot. J Fruit Sci. 2013;30:191-6.

24. Tao Y, Xie ZC, Glazebrook W, Chang J, Han HS, Zhu B, Zou T, Katagiri G. Quantitative nature of Arabidopsis responses during compatible and incompatible interactions with the bacterial pathogen Pseudomonas syringae. Plant Cell. 2003;15:317-30.

25. Tripathi P, Rabara RC, Langum TJ, et al. The WRKY transcription factor family in brachypodium distachyon. BMC Genomics. 2012;13:1-20.

26. Porter KR, Claude A, Fullam EF. A study of tissue culture cells by electron microscopy: method and preliminary observations. J Exp Med. 1945;81 (3):233-46.

27. Vogel J, Somerville S. Isolation and characterization of powdery mildewresistant Arabidopsis mutants. Proc Natl Acad Sci. 2000;97:1897-902.

28. Mortazavi A, Williams BA, McCue K, Schaeffer L, Wold B. Mapping and quantifying mammalian transcriptomes by RNA-Seq. Nat Methods. 2008;5:621-8.

29. Wang L, Feng Z, Wang X, Wang X, Zhang X. DEGseq: an R package for identifying differentially expressed genes from RNA-seq data. Bioinformatics. 2010;26(1):136-8.

30. Gillis J, Pavlidis P. The role of indirect connections in gene networks in predicting function. Bioinformatics. 2011;27:1860-6.

31. Zhang B, Horvath S. A general framework for weighted gene co-expression network analysis. Stat Appl Genet Mol Biol. 2005:4(7):1-37.

32. Ulker U, Shahid MM, Somssich IE. The WRKY70 transcription factor of Arabidopsis influences both the plant senescence and defense signaling pathways. Planta. 2007;226:125-37.

33. Kim SH, Gao F, Bhattacharjee S, Adiasor JA, Nam JC, Gassmann W. The Arabidopsis Resistance-Like Gene SNC1 Is Activated by Mutations in SRFR1 and Contributes to Resistance to the Bacterial Effector AvrRps4. PLoS Pathogens. 2010;6:1-14.

34. Bustin SA, Benes V, Garson JA, Hellemans J, Huggett J, Kubista M, Mueller R, Nolan T, Pfaffl MW, Shipley GL, Vandesompele JO, Wittwer CT. The MIQE guidelines: minimum information for publication of quantitative real-time PCR experiments. Clin Chem. 2009;55:1-14.

35. Vandesompele J, De Preter K, Pattyn F, Poppe B, Van Roy N, De Paepe A, Speleman F. Accurate normalization of real-time quantitative RT-PCR data bygeometric averaging of multiple internal control genes. Genome Biol. 2002;3:1-12.

36. Jian-Feng Li, Eunsook Park, Albrecht G von Arnim, Andreas Nebenführ. The FAST technique: a simplified Agrobacterium-based transformation method for transient gene expression analysis in seedlings of Arabidopsis and other plant species. Plant Methods 2009; 5:1-15

37. Davis AM, Hall A, Millar AJ, Darrah C, Davis SJ. Protocol: streamlined subprotocols for floral-dip transformation and selection of transformants in Arabidopsis thaliana. Plant Methods. 2009:5:1-7.

38. Wang W, Devoto A, Turner JG, Xiao S. Expression of the membraneassociated resistance protein RPW8 enhances basal defense against biotrophic pathogens. Mol Plant-Microbe Interact. 2009;20:966-76.

39. Yu Y, Xu W, Wang S, et al. VpRFP1, a novel C4C4-type RING finger protein gene from Chinese wild Vitis pseudoreticulata, functions as a transcriptional activator in defence response of grapevine. J Exp Bot. 2011;62:5671-82.

40. Melotto M, Underwood W, He SY. Role of stomata in plant innate immunity and foliar bacterial diseases. Annu Rev Phytopathol. 2008:46:101-22.

41. Zhang Y, Feng JC. Identification and characterization of the grape WRKY family. Biomed Res Int. 2014:1-14.

42. Altschul SF, Madden TL, Schaffer AA, et al. Gapped BLAST and PSI-BLAST: a new generation of protein database search programs. Nucleic Acids Res. 1997;25:3389-402.

43. Tatusov RL, Galperin MY, Natale DA, Koonin EV. The COG database: a tool for genome-scale analysis of protein functions and evolution. Nucleic Acids Res. 2000;28:33-6 2000

44. Kanehisa M, Goto S, Kawashima S, Okuno Y, Hattori M. The KEGG resource for deciphering the genome. Nucleic Acids Res. 2004;32:277-80.

45. Chen C, Chen Z. Isolation and characterization of two pathogen- and salicylic acid-induced genes encoding WRKY DNA-binding proteins from tobacco. Plant Mol Biol Repn. 2000;42:387-96.

46. Liqun Du ZC. Identification of genes encoding receptor-like protein kinases as possible targets of pathogen- and salicylic acid-induced WRKY DNAbinding proteins in Arabidopsis. Plant J. 2000;24:837-47.
47. Eulgem T, Rushton PJ, Robatzek S, Somssich IE. The WRKY superfamily of plant transcription factors. Trends Plant Sci. 2004;5:199-206.

48. Ulker B, Somssich IE. WRKY transcription factors: from DNA binding towards biological function. Curr Opin Plant Biol. 2004;7:491-8.

49. Eulgem T, Somssich IE. Networks of WRKY transcription factors in defense signaling. Curr Opin Plant Biol. 2007;10:366-71.

50. Grimplet J, Adam-Blondon A-F, Bert P-F, Bitz O, Cantu D, Davies C, Delrot S, Pezzotti M, Rombauts S, Cramer GR. The grapevine gene nomenclature system. BMC Genomics. 2014;15:1077.

51. Yamasaki K, Kigawa T, Inoue M, Watanabe S, Tateno M, Seki M, Shinozaki K, Yokoyama S. Structures and evolutionary origins of plant-specific transcription factor DNA-binding domains. Plant Physiol Biochem. 2008;46:394-401.

52. Polesani M, Bortesi L, Ferrarini A, et al. General and species-specific transcriptional responses to downy mildew infection in a susceptible (Vitis vinifera) and a resistant (V. riparia) grapevine species. BMC Genomics. 2010;11:1-16.

53. Jones JD, Dangl JL. The plant immune system. Nature. 2006;444:323-9.

54. Grenville-Briggs $\sqcup$, van West $P$. The biotrophic stages of oomycete-plant interactions. Adv Appl Microbiol. 2005;57:217-43.

55. Ali K, Maltese F, Zyprian E, Rex M, Choi YH, Verpoorte R. NMR metabolic fingerprinting based identification of grapevine metabolites associated with downy mildew resistance. J Agric Food Chem. 2009;57:9599-606.

56. Huckelhoven R. Cell wall-associated mechanisms of disease resistance and susceptibility. Annu Rev Phytopathol. 2007;45:101-27.

57. Jones DA, Takemoto D. Plant innate immunity - direct and indirect recognition of general and specific pathogen-associated molecules. Curr Opin Immunol. 2004;16:48-62.

58. Hacquard S, Spaepen S, Garrido-Oter R, Schulze-Lefert P. Interplay between innate immunity and the plant microbiota. Annu Rev Phytopathol. 2017;55: $565-89$.

59. Phukan UJ, Jeena GS, Shukla RK. WRKY transcription factors: molecular regulation and stress responses in plants. Front Plant Sci. 2016;7:1-14.

60. Rauscher M, Adam AL, Wirtz S, Guggenheim R, Mendgen K, Deising HB. PR1 protein inhibits the differentiation of rust infection hyphae in leaves of acquired resistant broad bean. Plant J. 1999;19:625-33.

61. Yu Y, Xu W, Wang J, et al. The Chinese wild grapevine (Vitis pseudoreticulata) E3 ubiquitin ligase Erysiphe necator-induced RING finger protein 1 (EIRP1) activates plant defense responses by inducing proteolysis of the VpWRKY11 transcription factor. New Phytol. 2013;200:834-46.

62. Greenberg JT, Yao N. The role and regulation of programmed cell death in plant-pathogen interactions. Cell Microbiol. 2004;6:201-11.

63. Broekaert WF, Delaure SL, De Bolle MF, Cammue BP. The role of ethylene in host-pathogen interactions. Annu Rev Phytopathol. 2006;44(2006):393-416.

64. Eulgem T. Dissecting the WRKY web of plant defense regulators. PLoS Pathog. 2006;2:1028-30.

65. Murray SL, Ingle RA, Petersen LN, Denby KJ. Basal resistance against Pseudomonas syringae in Arabidopsis involves WRKY53 and a protein with homology to a nematode resistance protein. Mol Plant-Microbe Interact. 2007;20:1431-8

Ready to submit your research? Choose BMC and benefit from:

- fast, convenient online submission

- thorough peer review by experienced researchers in your field

- rapid publication on acceptance

- support for research data, including large and complex data types

- gold Open Access which fosters wider collaboration and increased citations

- maximum visibility for your research: over $100 \mathrm{M}$ website views per year

At $\mathrm{BMC}$, research is always in progress.

Learn more biomedcentral.com/submissions 